\title{
When is the Ross operation a good option to treat aortic valve disease?
}

\author{
Tirone E. David, MD, Anna Woo, MD, Susan Armstrong, MSc, and Manjula Maganti, MSc
}

Objective: We sought to identify suitable patients for the Ross operation.

\begin{abstract}
Methods: A cohort of 212 patients (mean age, $34 \pm 9$ years; $66 \%$ men; $82 \%$ with congenital aortic valve disease) underwent the Ross operation and was prospectively followed with clinical evaluations and echocardiographic analysis for 3.1 to 18 years (mean, $10.1 \pm 4.2$ years). In addition to longitudinal outcomes determined by means of Kaplan-Meier analysis, Cox regression analysis was used to identify predictors of valve failure.
\end{abstract}

Results: There were 1 operative and 4 late deaths, none of which were valve related. Survival at 15 years was $96.6 \% \pm 1.5 \%$ and similar to that seen in the general population matched for age and sex. There were 20 reoperations: 13 in the pulmonary autograft, 3 in the pulmonary homograft, and 4 others. Freedom from reoperation in the pulmonary autograft at 15 years was $92.1 \% \pm 2.3 \%$. Aortic insufficiency was the only independent predictor of reoperation. Freedom from moderate or severe aortic insufficiency at 15 years was $89.7 \%$, and greater than mild aortic insufficiency was $63.2 \%$. Male sex, aortic/pulmonary annular mismatch, aortic annulus of $27 \mathrm{~mm}$ or larger, and preoperative aortic insufficiency were associated with higher risk of late aortic insufficiency by means of log-rank analysis. Cox regression analysis identified male sex as the only independent predictor of postoperative aortic insufficiency. Freedom from moderate or severe pulmonary insufficiency, peak gradient of $40 \mathrm{~mm} \mathrm{Hg}$ or greater, or both at 15 years was $70.8 \% \pm 6.8 \%$, and event-free survival was $81 \% \pm 3.7 \%$.

Conclusions: The Ross operation provided suboptimal results in male patients with aortic insufficiency. The best outcomes were in female patients, those with aortic stenosis, and those with an aortic annulus of less than $27 \mathrm{~mm}$ in diameter. (J Thorac Cardiovasc Surg 2010;139:68-75)

The enthusiasm for the Ross operation began to fade when surgeons recognized its fallibility early on in this millennium..$^{1-3}$ Dilation of the neoaortic root was thought to be the principal cause of aortic insufficiency (AI) and valve failure. ${ }^{1-3}$ Because dilation is less likely to occur when subcoronary implantation or aortic root inclusion techniques are used, ${ }^{1}$ one would expect better long-term outcomes with these approaches than with the technique of aortic root replacement, but a recent study suggests that the development of late AI caused by degeneration of the pulmonary cusps remains a problem regardless of the technique of implantation. ${ }^{4}$ Degenerative changes in the pulmonary root are commonly seen in patients with bicuspid aortic valve disease, which is the most common indication for the Ross operation in North America. ${ }^{5}$ It remains unknown whether these arterial wall changes might also affect the pulmonary cusps. For all these reasons, we do not know which patients, if any, would benefit from the Ross operation. This study attempts to answer this question by examining the factors

From the Cardiac Program of the Peter Munk Cardiac Centre at Toronto General Hospital and the University of Toronto, Toronto, Ontario, Canada.

Read at the Eight-ninth Annual Meeting of The American Association for Thoracic Surgery, Boston, Mass, May 9-13, 2009.

Received for publication April 29, 2009; revisions received July 12, 2009; accepted for publication Sept 30, 2009.

Address for reprints: Tirone E. David, MD, 200 Elizabeth St 4N457, Toronto, Ontario M5G 2C4, Canada (E-mail: tirone.david@uhn.on.ca).

$0022-5223 / \$ 36.00$

Copyright (c) 2010 by American Association for Thoracic Surgery doi:10.1016/j.jtcvs.2009.09.053 associated with the development of $\mathrm{AI}$ and reoperations after the Ross operation.

\section{MATERIALS AND METHODS}

From 1990 to 2004, 212 consecutive patients underwent Ross operations performed by 1 surgeon. Table 1 shows the clinical profile of all patients.

\section{Operative Techniques}

The diameters of the aortic annulus and sinotubular junction were measured with metric sizers after excision of the diseased aortic valve. The sinotubular junction of the pulmonary autograft was also measured, and the diameter of the pulmonary annulus was estimated to be $10 \%$ larger than the diameter of the sinotubular junction. If the diameter of the aortic annulus was more than $2 \mathrm{~mm}$ larger than the estimated diameter of the pulmonary annulus, the aortic annulus was surgically reduced before the pulmonary autograft was sutured in the left ventricular outflow tract. Similarly, if the aortic sinotubular junction was larger than the pulmonary sinotubular junction by more than $2 \mathrm{~mm}$, the aortic sinotubular junction and ascending aorta were plicated before the autograft was sutured within the aortic root or to the ascending aorta. ${ }^{6}$ The mean diameter of the aortic annulus was $26.75 \pm 3.69 \mathrm{~mm}$ (range, $17-40 \mathrm{~mm}$; $28.5 \pm 2.9 \mathrm{~mm}$ for men and $23.7 \pm 3.0 \mathrm{~mm}$ for women). The mean diameter of the pulmonary sinotubular junction was $22.90 \pm 1.91 \mathrm{~mm}$ (range, $18-27 \mathrm{~mm} ; 23.6 \pm 1.5$ $\mathrm{mm}$ for men and $21.7 \pm 3.0 \mathrm{~mm}$ for women). In addition, the aortic annulus diameters were transformed to $z$ values by using previously published methods. ${ }^{7}$ Reduction of the aortic annulus was performed in 90 patients, and reduction of the sinotubular junction was performed in 60 patients. The valve lesion in patients who had annular reduction was stenosis in 24 , insufficiency in 54, and mixed in 12 .

The pulmonary autograft was secured in the aortic position by using a modified subcoronary implantation or aortic root inclusion in 104 patients and as a freestanding neoaortic root in 108 patients. The decision to use an inclusion technique (subcoronary or root inclusion) or root replacement was largely dependent on the pathology of the aortic root, the sizes of the root 


\section{Abbreviations and Acronyms \\ $\mathrm{AI}=$ aortic insufficiency \\ $\mathrm{CI}=$ confidence interval \\ $\mathrm{HR}=$ hazard ratio}

and pulmonary autograft, and the anatomy of the coronary arteries. Thus patients with a small aortic root, previous aortic valve surgery, or an anomalous right coronary artery orifice had mostly aortic root replacement, whereas those with normal or dilated aortic roots had inclusion techniques. The noncoronary aortic sinus was always opened down to the level of the annulus when inclusion techniques were used to facilitate exposure. Reconstruction of the right side of the heart was performed with a pulmonary homograft in all patients except the first one of this series, who had an aortic valve homograft. In addition to the Ross operation, 25 patients had replacement of the ascending aorta, 4 patients had mitral valve repair, and 3 patients had coronary artery bypass because of suspected intraoperative ischemia.

\section{Follow-up}

The referring cardiologists followed the patients and provided us with annual clinical and echocardiographic data and a tape or CD with the most recent images obtained, which were reviewed by an experienced echocardiographer in our institution (AW). The clinical follow-up was complete and closed on September 30, 2008. It extended from 3.1 to 18 years (mean, $10.1 \pm 4.2$ years). Patients had 724 echocardiographic studies during the follow-up, but 8 patients had only 1 postoperative echocardiographic study; 199 had a study during the last 2 years of follow-up that was reviewed by one of us (AW). These postoperative studies were performed at a mean $9.5 \pm 3.6$ years (range, $0.1-17.7$ years) and closed on February 20, 2009. AI was graded according to the guidelines of the American Society of Echocardiography. ${ }^{7}$

\section{Statistical Analysis}

All statistical analyses were conducted with SAS (version 9.1) software for windows (SAS Institute, Inc, Cary, NC). Categorical variables were analyzed by using $\chi^{2}$ analyses or the Fisher's exact test and were expressed as percentages. All continuous variables were expressed as means \pm standard deviations, and means were compared with the Student $t$ test or Wilcoxon rank test. The Kaplan-Meier method was used to compare survival and freedom from morbid events. Age- and sex-matched Ontario general population survival estimates were obtained from the Life Table Template V1.2, a downloadable Excel spreadsheet available at http://www.healthinformation.on. ca. Cox regression methods were used to identify independent multivariable predictors of reoperation and $\mathrm{AI}$ and expressed as hazard ratios (HRs) and 95\% confidence intervals (CIs). The following variables were tested for their independent value as predictive of reoperation and development of AI: sex, age, functional class, preoperative aortic valve lesion, aortic valve pathology, pulmonary autograft implantation technique, aortic annulus diameter index, aortic annulus area index, surgical reduction of the aortic annulus, surgical reduction of the sinotubular junction, and replacement of the ascending aorta.

\section{RESULTS}

\section{Patients' Survival}

There were 1 operative and 4 late deaths. The operative death was due to a perioperative myocardial infarction, and the late deaths were sudden in 1 patient and not cardiovascular system related in 3 patients. Patients' survival at
TABLE 1. Clinical profile of patients

\begin{tabular}{|c|c|}
\hline No. of patients & 212 \\
\hline Age (mean $\pm S D), y$ & $34.6 \pm 9.4$ \\
\hline Range & $16-63$ \\
\hline \multicolumn{2}{|l|}{ Sex } \\
\hline Male & $140(66)$ \\
\hline Female & $72(34)$ \\
\hline \multicolumn{2}{|l|}{ Associated diseases } \\
\hline Diabetes & $2(0.9)$ \\
\hline Hypertension & $29(13.6)$ \\
\hline Hypercholesterolemia & $20(9.4)$ \\
\hline Chronic obstructive & $5(2.3)$ \\
\hline \multicolumn{2}{|l|}{ pulmonary disease } \\
\hline Previous TIA/stroke & $8(3.7)$ \\
\hline \multicolumn{2}{|l|}{ NYHA functional class } \\
\hline I & $41(19.3)$ \\
\hline II & $135(63.6)$ \\
\hline III & $26(12.2)$ \\
\hline IV & $10(4.7)$ \\
\hline \multicolumn{2}{|l|}{ Infective endocarditis } \\
\hline Healed & $13(6.1)$ \\
\hline Active & $2(0.9)$ \\
\hline \multicolumn{2}{|l|}{ Previous cardiac surgery } \\
\hline Aortic valve repair & $18(8.5)$ \\
\hline Aortic valve replacement & $12(5.6)$ \\
\hline Mitral valve repair & 1 \\
\hline \multicolumn{2}{|c|}{ Left ventricular ejection fraction } \\
\hline$>54 \%$ & $127(60)$ \\
\hline $40 \%-54 \%$ & $67(32)$ \\
\hline$<40 \%$ & $18(9)$ \\
\hline Mitral regurgitation & $3(1.4)$ \\
\hline \multicolumn{2}{|l|}{ Aortic valve disease } \\
\hline Stenosis & $107(50.4)$ \\
\hline Insufficiency & $77(36.3)$ \\
\hline Mixed lesion & $28(13.2)$ \\
\hline \multicolumn{2}{|l|}{ Aortic valve pathology } \\
\hline Bicuspid & $152(71.7)$ \\
\hline Other congenital & $22(10.3)$ \\
\hline Prosthetic dysfunction & $10(4)$. \\
\hline Tricuspid calcific & $3(1.4)$ \\
\hline Rheumatic & $6(2.8)$ \\
\hline Miscellaneous & $19(9.0)$ \\
\hline \multicolumn{2}{|c|}{ Body surface area (mean $\pm \mathrm{SD}$ ), $\mathrm{m}^{2}$} \\
\hline Men & $1.97 \pm 0.17$ \\
\hline Women & $1.70 \pm 0.20$ \\
\hline
\end{tabular}

Percentages are shown in parentheses. $S D$, Standard deviation; $T I A$, transient ischemic attack; NYHA, New York Heart Association.

15 years was $96.6 \% \pm 1.5 \%$, and that of the general population matched for age and sex was $97.5 \%$, as shown in Figure 1.

\section{Thromboembolic Complications}

One patient had a transient ischemic attack 69 months postoperatively, and 2 had a stroke with complete recovery at 1 and 13 months postoperatively, respectively. The freedom from this complication at 15 years was $98.4 \% \pm 0.8 \%$. 


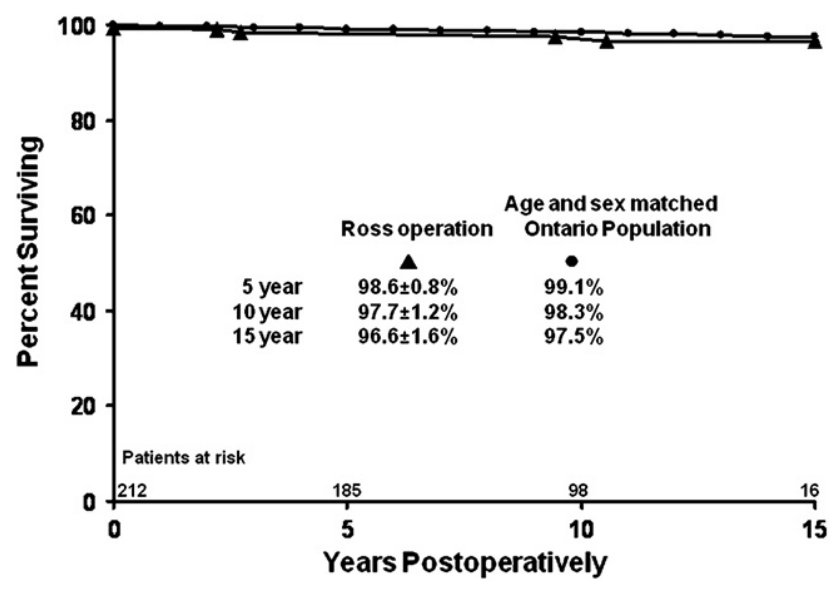

FIGURE 1. Survival after the Ross operation compared with that of the population in general matched for age and sex.

\section{Infective Endocarditis}

Three patients had infective endocarditis of the pulmonary homograft at 7.4, 8.5, and 10.1 years postoperatively, respectively. Two were successfully treated with antibiotics alone, and 1 underwent surgical intervention. The patient who underwent surgical intervention also had moderate AI caused by degenerative changes of the pulmonary autograft cusps and underwent successful aortic and pulmonary valve replacement. The freedom from infective endocarditis at 15 years was $97.5 \% \pm 1.4 \%$.

\section{Hemorrhagic Complications}

There was no late major hemorrhagic event, but only 1 patient was taking warfarin sodium.

\section{Reoperations}

Thirteen patients required reoperation on the pulmonary autograft: 1 soon after the initial operation because of AI caused by a technical error (treated with aortic root replacement), 9 for late AI caused by degeneration of the cusps of the pulmonary autograft (all 9 treated with aortic valve replacement), 1 for AI caused by dilation of the ascending aorta and sinotubular junction (treated with repair of 1-cusp prolapse and supracoronary replacement of the ascending aorta), and 2 for a false aneurysm of the pulmonary autograft/aortic annulus anastomosis (both were repaired). All patients survived reoperation. Freedom from reoperation on the pulmonary autograft at 15 years was $92.1 \% \pm 2.3 \%$. Table 2 shows the Kaplan-Meier estimates of freedom from reoperation on the pulmonary autograft in various subgroups of patients. Cox regression analysis identified preoperative AI (HR, 5.4; 95\% CI, $1.2-24 ; P=.03$ ) as the only independent predictor of reoperation on the pulmonary autograft.

Seven patients required other operations: 1 had replacement of the ascending aorta for aneurysm with normally functioning pulmonary autograft; 2 had pulmonary valve replacement and 1 had transcatheter implantation of a bioprosthetic valve in the failed pulmonary valve homograft; and 3 had coronary artery bypass surgery. Thus 20 patients had reoperation or reintervention during the follow-up period. Freedom from any reoperation or transcatheter valve implantation at 15 years was $85.2 \% \pm 3.5 \%$, and freedom from reoperation on the pulmonary homograft, including transcatheter valve implantation, was $97.3 \% \pm$ $1.6 \%$. Figure 2 shows freedom from reoperations. Table 2 shows freedom from reoperation on the pulmonary autograft in various subgroups of patients.

\section{Pathology of Explanted Pulmonary Autograft Valve}

Ten valves were explanted: 1 was normal, and 9 had gross evidence of degenerative changes with thinning and

TABLE 2. Freedom from reoperation on the pulmonary autograft

\begin{tabular}{|c|c|c|c|c|}
\hline & $5 y$ & $10 \mathrm{y}$ & $15 y$ & $P$ value \\
\hline \multicolumn{5}{|l|}{ Operative technique } \\
\hline Subcoronary/inclusion & $96.3 \pm 1.8(98)$ & $92.1 \pm 3.3(34)$ & $92.1 \pm 3.3(10)$ & \\
\hline Root replacement & $96.9 \pm 1.7(86)$ & $94.1 \pm 2.5(62)$ & $92.4 \pm 3.0(4)$ & .82 \\
\hline \multicolumn{5}{|l|}{ Aortic/pulmonary annulus } \\
\hline No mismatch & $98.2 \pm 1.2(98)$ & $98.2 \pm 1.2(44)$ & $98.2 \pm 1.2(6)$ & \\
\hline Mismatch & $94.6 \pm 2.3(85)$ & $88.5 \pm 3.6(52)$ & $86.5 \pm 4.0(8)$ & .01 \\
\hline \multicolumn{5}{|l|}{ Aortic annulus diameter } \\
\hline$<27 \mathrm{~mm}$ & $100(80)$ & $100(43)$ & $100(3)$ & \\
\hline$\geq 27 \mathrm{~mm}$ & $94.0 \pm 2.1(104)$ & $88.7 \pm 3.29(53)$ & $86.8 \pm 3.7(11)$ & .003 \\
\hline \multicolumn{5}{|l|}{ Aortic valve lesion } \\
\hline Stenosis & $99.0 \pm 0.9(93)$ & $97.4 \pm 1.9(47)$ & $97.4 \pm 1.9(3)$ & \\
\hline Insufficiency & $92.1 \pm 3.1(65)$ & $87.5 \pm 4.2(34)$ & $84.3 \pm 5.2(10)$ & \\
\hline Mixed & $100(26)$ & $3.7 \pm 6.0(15)$ & $93.7 \pm 6.0$ & .01 \\
\hline \multicolumn{5}{|l|}{ Sex } \\
\hline Female & $100(61)$ & $100(35)$ & $100(7)$ & \\
\hline Male & $94.8 \pm 1.8(140)$ & $90.0 \pm 2.9(61)$ & $88.1 \pm 3.4(7)$ & .03 \\
\hline
\end{tabular}

All values are shown in percentages. $P$ values were determined by using the log-rank test. Numbers in parentheses are patients at risk at that time interval. 




FIGURE 2. Freedom from any reoperation, reoperation on the pulmonary autograft, and reoperation or catheter-based pulmonary valve implantation.

stretching of the cusps and elongation of the free margins with prolapse. Three valves had cusp tears in the commissural areas. Microscopic analysis revealed fragmentation of the fibrous and elastic tissues and distortion of the normal histology. The basal region showed thickening caused by pannus.

\section{AI}

The most recently performed echocardiographic study before reoperation or death showed trace or no AI in 129 (61\%) patients, mild $\mathrm{AI}$ in $54(25.6 \%)$ patients, mild-tomoderate $\mathrm{AI}$ in $15(7.1 \%)$ patients, moderate $\mathrm{AI}$ in 8 $(3.8 \%)$ patients, and severe $\mathrm{AI}$ in $5(2.4 \%)$ patients. Figure 3 shows the freedom from moderate and severe AI (13 patients), as well as greater than mild AI (28 patients), based on 199 echocardiograms reviewed by us. Table 2 shows freedom from greater than mild AI in various subgroups of patients. Results were truncated at 14 years because of sample size. The cutoff for annulus size of less than 27 $\mathrm{mm}$ and $27 \mathrm{~mm}$ or larger was based on the mean aortic annulus diameter for all patients. Cox regression analysis identified male sex (HR, 8.8; 95\% CI, 2.1-33.7; $P=$ .003 ) as the only predictor of postoperative AI.

\section{Dilation of the Pulmonary Autograft}

Dilation of the pulmonary autograft, which was defined as diameter of the neoaortic root sinuses of greater than $39 \mathrm{~mm}$, occurred in $31(15.5 \%)$ of 199 studied patients. Congenital aortic valve disease was present in 26 of 31 patients, annular mismatch was present in 25 of 31 patients, preoperative AI was present in 16 of 31 patients, and aortic root replacement was present in 25 of 31 patients. Cox regression analysis disclosed preoperative AI (HR, 2.8; 95\% CI, 1.2-6.5; $P=$ .014 ) and aortic root replacement (HR, 5.9; 95\% CI, 2.016.7; $P=.001)$ as independent predictors of dilation of the pulmonary autograft sinuses. Only $7(3.5 \%)$ patients

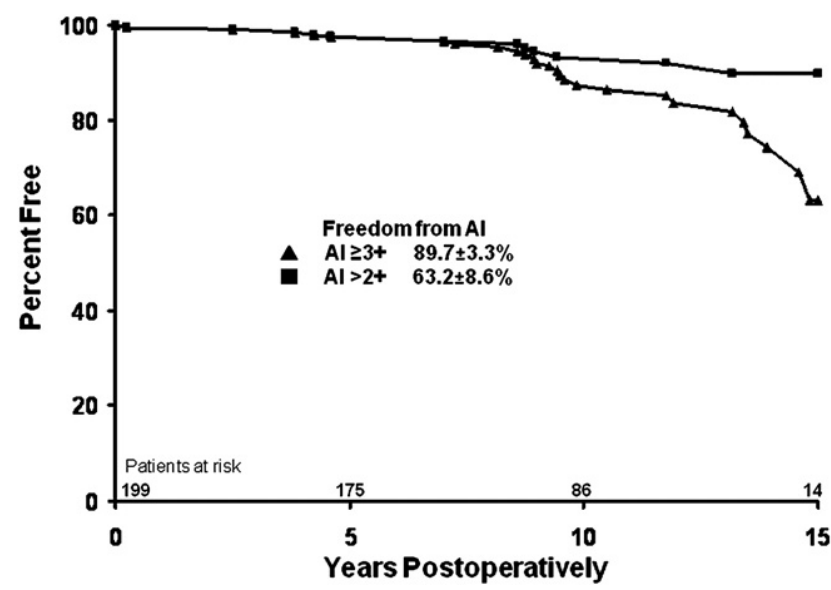

FIGURE 3. Freedom from moderate or severe $(\geq 3+)$ and greater than mild $(>2+)$ aortic insufficiency.

had a neoaortic root larger than $45 \mathrm{~mm}$, and only 1 has required replacement of the ascending aorta $(>50 \mathrm{~mm})$.

\section{Pulmonary Homograft}

Freedom from pulmonary valve insufficiency of moderate or severe degree, a peak systolic gradient of $40 \mathrm{~mm} \mathrm{Hg}$ or greater, or both at 5,10 , and 15 years was $100 \%, 95.1 \%$ $\pm 1.8 \%$, and $70.8 \% \pm 6.8 \%$, respectively.

\section{Late Functional Class and Event-Free Survival}

At the latest follow-up contact, $180(92 \%)$ patients were in functional class I, $12(6 \%)$ were in class II, and $4(2 \%)$ were in class III. The event-free survival at 15 years was $81 \% \pm 3.7 \%$.

\section{DISCUSSION}

The Ross operation is a complex procedure, and the operative mortality associated with it is quite variable among reports. In a recently published meta-analysis on outcomes of the Ross operation by Takkenberg and colleagues, ${ }^{8}$ the operative mortality in adult patients was $3.24 \%$, ranging from $0.3 \%$ to $6.8 \%$ among 12 studies. We believe that the mortality rate for aortic valve replacement in young adults should be $1 \%$ or less. ${ }^{9}$ In our series of patients undergoing the Ross operation, the operative mortality was $0.47 \%$, and the long-term survival was similar to that of the general population. Other reports on this operation in young adults showed survival similar to that of the general population. $^{7-12}$ However, this finding is not consistent in all studies on longitudinal outcomes of the Ross operation. ${ }^{8}$ One would expect a favorable long-term survival in comparison with other valves because of the pulmonary autograft's hemodynamic and biologic features, ${ }^{13}$ but given its technical complexity and the fact that single-valve disease is treated with an operation that involves replacement of 2 valves, 
TABLE 3. Freedom from aortic insufficiency greater than mild ( 28 patients)

\begin{tabular}{|c|c|c|c|c|}
\hline & $5 y$ & $10 \mathrm{y}$ & $14 y$ & $P$ value \\
\hline \multicolumn{5}{|l|}{ Operative technique } \\
\hline Subcoronary/inclusion & $97.0 \pm 1.6(80)$ & $81.9 \pm 5.2(44)$ & $75.5 \pm 6.5(12)$ & \\
\hline Root replacement & $97.6 \pm 1.6(94)$ & $91.7 \pm 3.2(43)$ & $73.6 \pm 8.1(11)$ & .599 \\
\hline \multicolumn{5}{|l|}{ Aortic/pulmonary annulus } \\
\hline No mismatch & $100(95)$ & $93.0 \pm 3.4(45)$ & $90.6 \pm 4.0(11)$ & \\
\hline Mismatch & $94.2 \pm 2.5(79)$ & $82.5 \pm 4.7(42)$ & $61.9 \pm 8.3(12)$ & .001 \\
\hline \multicolumn{5}{|l|}{ Aortic annulus diameter } \\
\hline$<27 \mathrm{~mm}$ & $100(77)$ & $93.2 \pm 3.7(36)$ & $86.0 \pm 7.2(9)$ & \\
\hline$\geq 27 \mathrm{~mm}$ & $95.3 \pm 2.0(97)$ & $83.9 \pm 3.9(51)$ & $66.9 \pm 6.5(14)$ & .007 \\
\hline \multicolumn{5}{|l|}{ Aortic valve lesion } \\
\hline Stenosis & $100(89)$ & $93.1 \pm 3.3(44)$ & $87.3 \pm 6.4(8)$ & \\
\hline Insufficiency & $92.8 \pm 3.1(61)$ & $80.7 \pm 5.7(29)$ & $64.8 \pm 8.6(11)$ & \\
\hline Mixed & $100(24)$ & $84.3 \pm 8.3(14)$ & $64.4 \pm 14.5(4)$ & .022 \\
\hline \multicolumn{5}{|l|}{ Sex } \\
\hline Female & $100(63)$ & $95.5 \pm 3.1(36)$ & $89.1 \pm 6.8(9)$ & \\
\hline Male & $95.9 \pm 1.7(111)$ & $82.9 \pm 4.2(51)$ & $65.8 \pm 7.3(14)$ & .001 \\
\hline
\end{tabular}

the overall balance might be equal to or even worse than that seen with other types of heart valve substitutes.

Early on in our experience with the Ross operation, we observed that the pulmonary and aortic roots often had different dimensions, and we had to reduce the diameter of the aortic annulus to match the smaller pulmonary annulus. ${ }^{6}$ This maneuver certainly prevented early postoperative AI, but as it turned out, mismatch in sizes between the aortic and pulmonary annuli was associated with an increased risk of late pulmonary autograft failure, as defined by the development of greater than mild AI. A dilated aortic annulus was commonly associated with incompetent congenital aortic valve disease, but it was also found in some patients with aortic stenosis and mixed lesions. Actually, the mean diameter of the aortic annulus in our patients was higher than normal when compared with values derived from measurement of aortic valve homografts by CryoLife, Inc (G. Kennesaw). ${ }^{14}$ There were no reoperations on the pulmonary autograft in patients with an aortic annulus of less than 27 $\mathrm{mm}$, and the incidence of greater than mild AI was much lower in patients with a smaller aortic annulus. A dilated aortic annulus is probably a marker of connective tissue disorder, which might predict premature degeneration of the pulmonary autograft cusps. Indeed, in this study degeneration of the pulmonary autograft cusps was present in 9 of 10 patients who had reoperations on the pulmonary autograft, all of whom had a dilated aortic annulus ( $\geq 27 \mathrm{~mm}$ ). Annular mismatch, an aortic annulus of $27 \mathrm{~mm}$ or larger, preoperative AI, and male sex were associated with higher probability of reoperation on the autograft and late postoperative AI by means of log-rank analysis, as shown in Tables 2 and 3. Cox regression analyses revealed that preoperative AI was the only independent predictor of reoperation on the pulmonary autograft, whereas male sex was the only predictor of greater than mild AI. The technique of implantation of the pulmonary autograft had no effect on freedom from reoperation or on the development of late AI.

The best outcomes in our series were in patients with a normal aortic annulus smaller than $27 \mathrm{~mm}$ in diameter and in women.

Elkins and associates ${ }^{10}$ reported on their 16-year results with the Ross operation in 487 patients, including 197 aged 18 years and less. The technique of aortic root replacement was used in $80 \%$ of their patients. The long-term survival paralleled but was lower than that of the general population matched for age, sex, and year of operation. Those investigators defined pulmonary autograft failure as the need for reoperation or valve-related death, and the freedom at 16 years was 74\% $\pm 5 \%$. Male sex and AI were identified as independent predictors of pulmonary autograft failure.

Böhm and coworkers ${ }^{15}$ from Germany recently reported another large series of Ross operations. They operated on 467 patients with a mean age of 42 years and used almost exclusively the technique of aortic root replacement. After a mean follow-up of 5.5 years, only 18 patients had reoperations on the pulmonary autograft, and the freedom from reoperation or AI greater than mild at 10 years was $94.2 \%$ $\pm 2.8 \%$. They found that pulmonary autograft regurgitation was 6 times more common in men than in women but made no inferences about valve lesion or aortic annulus size.

In previous publications we expressed concern about dilation of the pulmonary autograft when implanted as a freestanding aortic root and suggested that the modified subcoronary or aortic root inclusion technique might prevent dilation. ${ }^{6}$ Although the pulmonary autograft dilates after being transferred to the systemic circulation, the present study indicates that the degree of dilation became a problem only in a small proportion of patients and 
occurred largely in those who underwent aortic root replacement and had preoperative AI caused by congenital aortic valve disease. Thus it is possible that the operative technique plays a role on late dilation and eventual failure of the pulmonary autograft, but our sample size was relatively small to demonstrate that.

In addition to the complexity of the Ross operation, another common criticism is that it requires a pulmonary homograft, which can also fail. Failure of the pulmonary homograft is a problem in young children but less so in young adults and older patients. ${ }^{16-18}$ Actually, the pulmonary homograft in young children seems to be more durable after the Ross operation than after other types of right ventricular outflow tract reconstruction for congenital heart disease. ${ }^{18}$ In our series only 3 patients have required reintervention for a freedom from reoperation of $97.3 \% \pm 1.6 \%$, but the freedom from pulmonary dysfunction, as defined as moderate or severe pulmonary insufficiency, a peak systolic gradient of $40 \mathrm{~mm}$ $\mathrm{Hg}$ or greater, or both at 15 years, was $70.8 \% \pm 6.8 \%$. The fate of the pulmonary homograft after the Ross operation varies among reports depending on how dysfunction is defined, but it is not a serious problem. ${ }^{10-12}$ In addition, with the advent of catheter-based pulmonary valve implantation, this problem is further mitigated.

In spite of all the valve-related problems described in the study, $185(87 \%)$ of 212 patients were free from any cardiovascular complications after a mean follow-up of 10 years. If patients with a dilated aortic annulus were excluded, the results were indeed excellent and probably compare favorably with those of other types of heart valve substitutes for aortic valve replacement in young adults. ${ }^{18-20}$

In summary, this study showed excellent long-term outcomes after the Ross operation in female patients and in other patients with an aortic annulus less than $27 \mathrm{~mm}$ in diameter. Patients with aortic stenosis are more likely to do well than those with AI. The technique of implantation had no demonstrable effect on the fate of the operation, but patients with a dilated aortic annulus did not fare well, and reduction of the aortic annulus at the time of surgical intervention did not resolve the problem, suggesting that a dilated aortic annulus might be a marker for premature degeneration of the pulmonary autograft cusps.

\section{References}

1. David TE, Omran A, Ivanov J, Armstrong S, de Sa MP, Sonnenberg B, et al. Dilation of the pulmonary autograft after the Ross procedure. J Thorac Cardiovasc Surg. 2000;119:210-20.

2. Kouchoukos NT, Masetti P, Nickerson NJ, Castner CF, Shannon WD, DávilaRomán VG. The Ross procedure: long-term clinical and echocardiographic follow-up. Ann Thorac Surg. 2004;78:773-81.

3. Takkenberg JJ, van Herwerden LA, Galema TW, Bekkers JA, KleyburgLinkers VE, Eijkemans MJ, et al. Serial echocardiographic assessment of neo-aortic regurgitation and root dimensions after the modified Ross procedure. J Heart Valve Dis. 2006;15:100-6.

4. de Kerchove L, Rubay J, Pasquet A, Poncelet A, Ovaert C, Pirotte M, et al. Ross operation in the adult: long-term outcomes after root replacement and inclusion techniques. Ann Thorac Surg. 2009;87:95-102.
5. de Sa M, Moshkovitz Y, Butany J, David TE. Histologic abnormalities of the aorta and pulmonary trunk in patients with aortic valve disease: clinical relevance to the Ross procedure. J Thorac Cardiovasc Surg. 1999;118:588-94.

6. David TE, Omran A, Webb G, Rakowski H, Armstrong S, Sun Z. Geometric mismatch of the aortic and pulmonary roots causes aortic insufficiency after the Ross procedure. J Thorac Cardiovasc Surg. 1996;112:1231-9.

7. Zoghbi WA, Enriquez-Sarano M, Foster E, Grayburn PA, Kraft CD, Levine RA, et al. Recommendations for evaluation of the severity of native valvular regurgitation with two-dimensional and Doppler echocardiography. J Am Soc Echocardiogr. 2003;16:777-802.

8. Takkenberg JJM, Klieverik LMA, Schoof PH, Van Suylen RJ, van Herwerden LA, Zondervan PE, et al. The Ross procedure: a systematic review and meta-analysis. Circulation. 2009;119:222-8.

9. David TE. The Ross procedure at the crossroads. Circulation. 2009;119:207-9.

10. Elkins RC, Thompson DM, Lane MM, Elkins CC, Peyton MD. Ross operation: 16-year experience. J Thorac Cardiovasc Surg. 2008;136:623-30.

11. Klieverik LM, Takkenberg JJ, Bekkers JA, Roos-Hesselink JW, Witsenburg M, Bogers AJ. The Ross operation: a Trojan horse? Eur Heart J. 2007;28:1993-2000.

12. Yacoub MH, Klieverik LM, Melina G, Edwards SE, Sarathchandra P, Bogers AJ, et al. An evaluation of the Ross operation in adults. J Heart Valve Dis. 2006;15: 531-9.

13. Laforest I, Dumesnil JG, Briand M, Cartier PC, Pibarot P. Hemodynamic performance at rest and during exercise after aortic valve replacement: comparison of pulmonary autografts versus aortic homografts. Circulation. 2002;106:I57-62.

14. Capps SB, Elkins RC, Fronk DM. Body surface area as a predictor of aortic and pulmonary annulus valve diameter. J Thorac Cardiovasc Surg. 2000;119:975-82.

15. Böhm JO, Hemmer W, Rein JG, et al. A Single-institution experience with the Ross operation over 11 years. Ann Thorac Surg. 2009;87:514-20.

16. Boethig D, Goerler H, Westhoff-Bleck M, Ono M, Daiber A, Haverich A, et al. Evaluation of 188 consecutive homografts implanted in pulmonary position after 20 years. Eur J Cardiothorac Surg. 2007;32:133-42.

17. Brown JW, Ruzmetov M, Rodefeld MD, Turrentine MW. Right ventricular outflow tract reconstruction in Ross Patients: does the homograft fare better? Ann Thorac Surg. 2008;86:1607-12.

18. Takkenberg JJ, Eijkemans MJ, van Herweden LA, Steyerberg EW, Lane MM, Elkins RC, et al. Prognosis after aortic valve root replacement with cryopreserved allografts in adults. Ann Thorac Surg. 2003;75:1482-9.

19. Smedira NG, Blackstone EH, Roselli EE, Laffey CC, Cosgrove DM. Are allografts the biologic valve of choice for aortic valve replacement in nonelderly patients? Comparison of explantation for structural valve deterioration of allograft and pericardial prostheses. J Thorac Cardiovasc Surg. 2006;131:558-64.

20. Hammermeister K, Sethi GK, Henderson WG, Grover FL, Oprian C, Rahimtoola SH. Outcomes 15 years after valve replacement with a mechanical versus a bioprosthetic valve: final report of the Veterans Affairs randomized trial. J Am Coll Cardiol. 2000;36:1152-8.

\section{Discussion}

Dr Lawrence Cohn (Boston, Mass). Tirone, as usual, an excellent paper with superb results. I have no conflicts to present. I think especially notable is the superb survival, as it should be in this very young group of adults. I think the real message is that proper patients should have excellent and good early and late survival; the gender observation is obviously quite new.

The message I got from your paper is that you should not do a Ross operation if you have severe aortic regurgitation with a bicuspid aortic valve or when the aortic annulus is quite a bit bigger than the pulmonary valve annulus. That seems very, very clear.

You did annular and sinotubular banding procedures. I am concluding that they were not effective. Is that fair to say?

Dr David. That's correct. I do believe that a dilated aortic annulus is a marker of premature degenerative disease of a pulmonary valve; work that we have been doing for 20 years now.

Dr Cohn. Agreed. Would it be fair then to say that aortic regurgitation in a bicuspid aortic valve is a contraindication to the Ross operation? 
Dr David. I no longer do the Ross procedure on these patients because surgical adjustment of the dilated annulus did not prevent the pulmonary cusps to degenerate prematurely.

Dr Cohn. Your reoperation rate for the pulmonary autograft was very, very good. I found it fascinating that you did equally a number of subcoronary procedures, as the original Ross procedure was conceived, as opposed to the root. Are these intermingled? How do you choose to do one or the other, or were these sequential? In all the ones that we did, a much smaller series to be sure, but the only ones I did were all root replacement.

Dr David. Our experience with aortic valve homograft preceded the pulmonary autograft. I started doing aortic homografts when I started practicing, and always opened the aortic root down to the aortic annulus to increase exposure of the right and left aortic sinuses. If the relationship between the coronary artery orifices and annulus was fairly normal, that is, the coronary artery was in the center of the sinus, we scalloped the left and the right, did subcoronary for the left and right, left the noncoronary sinus of the donor valve was left intact, and did the upper anastomosis, closed the aortic root at the end of the operation only if there was enough tissue. If there was enough, we used a patch of autologous pericardium. So there was a reason to do one or the other procedure. If the anatomy was not normal, if the coronaries were at 180 degrees, it was difficult to align a tricuspid valve into it and those patients had root replacement. And that is the bias perhaps that cannot be measured. It was an intraoperative decision to do one or the other procedure.

Dr Cohn. My last question relates to the reconstruction of the pulmonary homograft. In our smaller series we found several patients that ended up with pulmonary trunk hyperplasia, endothelial hyperplasia. Have you seen this in any of the patients, because you had a moderate number that had pulmonary insufficiency and/or pulmonary gradients greater than 40 ? As you said, you readjusted those numbers from the abstract. Have you seen this and how do you treat these people and when do you feel it is time to intervene when you have this sort of progressive pulmonary stenosis or pulmonary regurgitation?

Dr David. Every patient who had a mean systolic gradient by echo more than 40 was a potential candidate to have pulmonary valve intervention. Those patients underwent heart catheterization, and it was amazing how often the echo gradients were incorrect and at catheterization we found only mean gradients of 10 to 20 and, because the patients had no right ventricular hypertrophy of dysfunction, we left them alone. The stenosis almost invariably is at the pulmonary artery level, not at the cusps. The cusps remain pretty normal and the pulmonary artery of the donor becomes stenotic. If it is possible that is caused by inflammatory reaction. Since it could be due inflammation, we treated these patients with a high dose of aspirin, but aspirin is the only thing we give. I don't know if that inflammatory reaction can be prevented. With advent of percutaneous valve deployment, managing pulmonary homograft dysfunction should become less of problematic in the future.

Dr Cohn. Super paper.

Dr David. Thank you.

Dr Peter Skillington (Melbourne, Australia). Thank you very much, Tirone. It was a very good paper. I just wonder what your current approach is now then for a patient with coronary arteries abnormally positioned? Is it a subcoronary?
Dr David. Scalloped on the left and right, and then we leave the noncoronary sinus of the pulmonary autograft intact, do a distal anastomosis, unclamp, and then after you do the echo, if there is enough tissue, close the root primarily around the modified subcoronary. If there is not enough tissue, we put a patch of pericardium there to close.

Our intention was to prove that root replacement was bad. Our data doesn't support that.

Dr Skillington. You are not the first one to note that female patients seem to do better. Can you speculate as to the reasons for that?

Dr David. I initially thought because most of them have aortic stenosis as opposed to insufficiency. I don't know enough about the multivariable analysis but our biostatistician reran 3 or 4 times different models, and women always emerged as a predictor of better outcome. I don't know the answer. As you said, we are not the first ones to point this out. Ronald Elkins with a much larger series showed that female was a protecting effect as well, and Dr Elkins had done mostly root replacement.

Dr Skillington. My final question, what do you think the really long-term fate of the pulmonary allograft valve is going to be?

Dr David. I think it is like the aortic homograft and is going to fail, unfortunately. However, if at 20 years half of them are still functioning well and they can deploy a percutaneous valve that might last another 15, 20 years, it is not that big a deal. Obviously, we had to adapt your practice to our environment. Where I practice, anticoagulation on a 25-year-old is a major problem. It is not a minor thing for either young men or women to have a mechanical valve and take Coumadin. So we continue seeking for a better biological valve. I don't think the Ross is a bad option, and I have to tell you that, since we discovered this last year, we have done another 20 patients. We are doing a Ross routinely again for anyone with aortic stenosis who does not wish to take anticoagulants. And, of course, one has to be relatively young. It doesn't make any sense to do it in a 70-year-old, but in a 50-year-old or younger, why not?

Dr A. Sampath Kumar (New Delhi, India). Dr David, I must congratulate you on a wonderful experience and a good presentation on this large series. We started doing Ross procedures in 1993, and from the very first case we did only root replacements. We never did a scalloped subcoronary. And we did not do a Ross procedure if the aortic root annulus measured more than $30 \mathrm{~mm}$. I think your observation is very correct and I agree with you that if there is aortic root dilatation, we believe $30 \mathrm{~mm}$ is the limit. Beyond that, the Ross procedure is going to fail. The other observation we made in rheumatics is that the pulmonary valve is already subjected to high pressure because of the pulmonary hypertension and is a much better autograft to use as a replacement for the aortic valve.

Thank you very much for giving me this opportunity to comment.

Dr David. A retrospective review from the tissue bank in Europe supports what you are saying. There was a time in the early 1990s that we would use a pulmonary homograft to replace the aortic valve, and early failures were common. At five years, more than half of them failed. At 10 years, approximately 1 in 3 was still functioning as well as aortic valve homograft. They went back to the donors, and the valves of donors with pulmonary hypertension did as well as aortic homograft. They probably had had heart-lung transplant, and the pulmonary valves of those donors tolerated systemic 
pressure much better, suggesting that the pulmonary valve might adapt to high pressure. So the rheumatic who has pulmonary hypertension is likely to do better because the pulmonary valve is indeed already prepared to sustain systemic pressure.

Dr Kumar. There are several advantages with pulmonary hypertension. First, the autograft is easier to take out because the muscle is quite thick and you are not likely to injure the first septal artery. The pulmonary artery wall is pretty thick, so it is very good; it has already adapted to the high pressures in the aortic position. So I think it is a good advantage to do it in patients with pulmonary hypertension. Thank you.

Dr John Fehrenbacher (Indianapolis, Ind). I do have a disclosure with CryoLife. I am a consultant.

Dr David, remarkable results. I don't know in the literature that any other mechanical or tissue valve has almost a 97\% 15-year survival, but maybe in your hands, mechanical or tissue valves do. Knowing these results, why not use the Ross in somebody who has aortic insufficiency when it provides such excellent 15 -year survival versus putting in a mechanical or a tissue valve that may not have these excellent results?

Dr David. Well, what I didn't say was that all patients who had reoperations did not die. So the most serious valve-related complication in this series, which was valve failure, was not a cause of death and this may have contributed to a late survival similar to that of a matched general population. Thus, if no patient died from a valve-related complication, one should expect death only by the same causes and in the population in general.

The problems of aortic insufficiency are more complicated. In 20 -year-old patients who have a $30 \%-40 \%$ chance to have aortic insufficiency at 15 years, I am not so sure the Ross is much better than a tissue valve, particularly the newer tissue valves. So the Ross procedure should give the patient results better than existing bioprosthetic valves. Bioprosthetic valves are not bad anymore. Some of them are actually very good. We have experience with 2 of them: Carpentier-Edwards Perimount and Hancock II. We practically have no reoperation for valve failure during the first decade. In the second decade they come back but I think it parallels the failures of the Ross for aortic insufficiency, but not for aortic stenosis. So I think the Ross is an ideal procedure for a stenotic aortic valve. It is less than perfect for aortic insufficiency.

My main concern is that aortic insufficiency in congenital aortic valve disease may be a marker for premature degenerative process in a pulmonary valve. We published a study suggesting that bicuspid aortic valve was the bad fellow. I think we were wrong. It was not bicuspid aortic valve; it was the bicuspid aortic valve with dilated aortic annulus that was bad. This does not apply to rheumatic aortic insufficiency, as Professor Kumar mentioned. 